\title{
Xanthine Dehydrogenase/Oxidase
}

National Cancer Institute

\section{Source}

National Cancer Institute. Xanthine Dehydrogenase/Oxidase. NCI Thesaurus. Code C39587.

Xanthine dehydrogenase/oxidase (1333 aa, 146 kDa) is encoded by the human XDH gene. This protein is involved in purine degradation. 